\title{
Tribological Performance of Non-halogenated Phosphonium lonic Liquids as Additives to Polypropylene and Lithium-Complex Greases
}

\author{
Moritz Ploss $^{1} \cdot$ Yiyuan Tian $^{1} \cdot$ Sosaku Yoshikawa ${ }^{1,2} \cdot$ René Westbroek $^{3} \cdot$ Johan Leckner $^{3} \cdot$ Sergei Glavatskih $^{1,4} \mathbb{D}$
}

Received: 17 July 2019 / Accepted: 23 October 2019 / Published online: 16 November 2019

(c) The Author(s) 2019

\begin{abstract}
Four non-halogenated ionic liquids (ILs) with trihexyl(tetradecyl)phosphonium cation are tested as lubricant additives to polypropylene (PP) and lithium-complex (LiX) greases. In pin-on-disk tests at elevated temperatures, the addition of an IL with bis(oxalato)borate ([BOB]) anion reduces wear by up to $50 \%$ when compared to the neat LiX base grease; an IL with bis(mandelato)borate ([BMB]) anion reduces friction by up to $60 \%$ for both $\mathrm{PP}$ and LiX. Elemental analysis reveals that oxygen-rich tribofilms help to reduce wear in case of [BOB], while the friction reduction observed for [BMB] is likely caused by adsorption processes. We find that temperature has a pronounced effect on additive expression, yet additive concentration is of minor importance under continuous sliding conditions. In contrast, rolling-sliding experiments at $90{ }^{\circ} \mathrm{C}$ show that the traction performance of LiX grease is dependent on additive concentration, revealing a reduction in traction by up to 30 and $40 \%$ for [BMB]- and [BOB]-containing ILs at concentrations of $10 \mathrm{wt} \%$. Finally, an IL with dicyanamide anion reduces friction and increases wear in pin-on-disk tests at room temperature, while an IL with bis-2,4,4-(trimethylpentyl) phosphinate anion increases wear, showing only limited potential as grease additives. Overall, this work demonstrates the ability of non-halogenated ILs to significantly extend grease performance limits.
\end{abstract}

Keywords Ionic liquid lubrication $\cdot$ Non-halogenated ionic liquids $\cdot$ Polypropylene grease $\cdot$ Lithium-complex grease

\section{Introduction}

Lubricating greases rely on carefully designed additive packages to reduce friction and wear under harsh operating conditions. While traditional additive formulations often contain considerable amounts of phosphorus, zinc, and sulfur, the growing need for sustainable lubrication technologies is limiting the use of these elements to ever-decreasing quantities [1]. Thus, the development of additives with reduced environmental impact has become a multidisciplinary challenge.

Sergei Glavatskih

segla@kth.se

1 System and Component Design, KTH Royal Institute of Technology, 10044 Stockholm, Sweden

2 Department of Mechanical Engineering, The University of Tokyo, Tokyo 113-8656, Japan

3 Axel Christiernsson International AB, 44911 Nol, Sweden

4 Department of Electromechanical, Systems and Metal Engineering, Ghent University, 9000 Ghent, Belgium
One class of additives that has been suggested in this context is ionic liquids (ILs), generally defined as salts with melting points below $100{ }^{\circ} \mathrm{C}$, fully composed of discrete ions. Due to a large number of possible ion combinations, their physicochemical properties can be tuned widely. Moreover, their polar nature eases their dissolution in polar liquids such as vegetable oils and esters [2-10], while many ILs also show reasonably good solubility in poly-alpha-olefins (PAOs) [11-14] and mineral oils [14-18].

So far, various ILs have been studied for their use in tribological systems, both as neat lubricants and lubricant additives [19-24]. The focus of research has been on ILs with imidazolium, phosphonium, ammonium, and pyridinium cations in combination with halogenated anions, such as tetrafluoroborate, bis(trifluoromethylsulfonyl)imide, and hexafluorophosphate. Although this so-called second generation of ILs showed remarkable performance in basic tribological testing, their claimed environmental advantage has been questioned repeatedly $[25,26]$, mostly because of susceptibility to hydrolysis (and therefore corrosion) and the formation of toxic halogen compounds, such as hydrogen fluoride. 
Table 1 Base grease properties

\begin{tabular}{|c|c|c|c|c|c|c|}
\hline \multirow[t]{2}{*}{ Designation } & \multirow[t]{2}{*}{ Thickener type } & \multirow{2}{*}{$\begin{array}{l}\text { Thickener content } \\
\text { [wt } \%]\end{array}$} & \multirow[t]{2}{*}{ Base oil composition [wt $\%$ ] } & \multicolumn{2}{|c|}{ Base oil viscosity [cSt] } & \multirow[t]{2}{*}{ NLGI grade } \\
\hline & & & & $40^{\circ} \mathrm{C}$ & $100{ }^{\circ} \mathrm{C}$ & \\
\hline PP & Polypropylene & 12.5 & $93.7 \mathrm{PAO}+6.3$ adipate ester & 61.6 & 9.7 & 2 \\
\hline LiX & Lithium-complex soap & 20.6 & & 63.5 & 9.8 & \\
\hline
\end{tabular}

Table 2 Ionic liquids with trihexyl(tetradecyl)phosphonium cation

\begin{tabular}{lllll}
\hline & {$\left[\mathrm{P}_{6,6,6,14}\right][\mathrm{BMB}]$} & {$\left[\mathrm{P}_{6,6,6,14}\right][\mathrm{BOB}]$} & {$\left[\mathrm{P}_{6,6,6,14}\right][\mathrm{BMPP}]$} & {$\left[\mathrm{P}_{6,6,6,14}\right][\mathrm{DCA}]$} \\
\hline Anion & $\begin{array}{l}\text { bis(mandelato)borate } \\
\text { Synthesis }\end{array}$ & $\begin{array}{l}\text { bis(oxalato)borate } \\
\text { See Ref. [27] }\end{array}$ & $\begin{array}{l}\text { bis-2,4,4-(trimethylpentyl)phosphinate } \\
\text { From Cytec }\end{array}$ & $\begin{array}{l}\text { Dicyanamide } \\
\text { From Cytec }\end{array}$ \\
\hline Structure cation & & Structure anion &
\end{tabular}

In earlier work, our group has synthesized non-halogenated, orthoborate ILs that enable low friction and wear in aluminum-steel [27] and steel-steel [28, 29] sliding contacts, both as neat lubricants and additives to oils. Due to their boron-based anions, these ILs potentially exhibit good tribological performance [30] with reduced environmental impact; however, a detailed assessment of these and other properties is the subject of the current and future work.

Meanwhile, further tribological research is required in order to understand how the lubrication performance of orthoborate ILs is related to their chemical structure and interaction with the base lubricant. For lubricating greases, studies have so far been limited to halogenated ILs [31-40] or cases where ILs are used to synthesize thickener-free "ionic grease lubricants" [41]. In the former case, reductions in friction [31-33, 35, 36, 38, 40] and wear [31-35, 37, $38,40]$ are well documented, typically for IL concentrations of $1-5 \mathrm{wt} \%$.

Focusing on phosphonium ILs, the present study aims to further the understanding of IL performance in lubricating greases. In particular, we are comparing grease blends based on polypropylene (PP) and lithium-complex (LiX) base greases. While LiX grease is the industry standard for lubricating grease, PP has only caught the attention of the research community in the mid-1990s [42]. So far, studies have shown promising tribological performance for this grease type [43-46], which is of interest due to its non-polar thickener, good film-forming properties [47], comparatively high oil bleed rate at low temperatures, and compatibility with common grease additives [48].
We present a comparison of the friction and wear performance of IL-containing $\mathrm{LiX}$ and PP grease blends. Four non-halogenated ILs are studied as candidate additives, and the influence of anion type and IL content is assessed in initial screening tests. Variations of temperature and slideto-roll ratio (SRR) are then performed for two selected ILs. Finally, scanning electron microscopy (SEM) and energydispersive X-ray (EDX) spectroscopy are used to analyze the worn surfaces.

\section{Materials and Methods}

\subsection{Grease Blends}

Four ILs with trihexyl(tetradecyl)phosphonium cation were blended with PP and LiX greases in IL concentrations of 2, 5 , and $10 \mathrm{wt} \%$. To synthesize the grease blends, greases and ILs were mixed in a Flacktek Speedmixer DAC 600.1 FVZ. Each sample was mixed at $1400 \mathrm{rpm}$ during two cycles of $5 \mathrm{~min}$. In between the cycles, the grease was carefully scraped from the side of the container in order to guarantee a homogeneous sample. Table 1 gives an overview of base grease properties; the chemical structures of the ILs are summarized in Table 2.

To increase polarity and thereby facilitate the saponification reaction, a polar base oil component (adipate ester) was added to the LiX base oil blend. This is standard procedure in industrial grease manufacturing when non-polar base oils, such as PAO, are used. The presence of a polar component facilitates a rapid and complete reaction, ensuring that the 
Table 3 Test conditions for pin-on-disk (POD) and ball-on-disk (SRR) experiments with entrainment speed $v$, slide-to-roll ratio SRR, sliding distance $s$, mean Hertzian contact pressure $p_{\text {mean }}$, ambient temperature $\theta$, IL mass fraction $w_{\mathrm{IL}}$, and minimum number of repetitions $n$

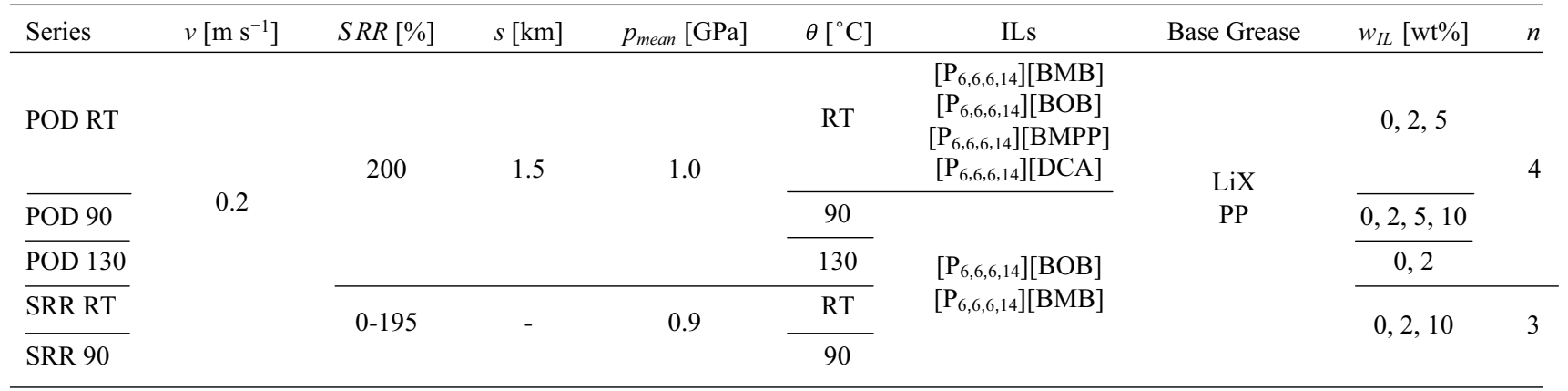

soap concentration in the final grease blend is not too high. While there is no technical reason to add adipate ester to PP grease, identical base oils were used for both base grease types in order to limit the number of experimental variables. Moreover, it is possible that the adipate ester improves IL solubility, and the effect is expected to be similar for both grease types.

A high pressure differential scanning calorimeter of type Mettler-Toledo HP DSC1 was used to determine oxidation onset temperature of the LiX grease and its blends with $\left[\mathrm{P}_{6,6,6,14}\right][\mathrm{BMB}]$ and $\left[\mathrm{P}_{6,6,6,14}\right][\mathrm{BOB}]$. The measurements were carried out in pure oxygen at $3.8 \mathrm{MPa}$ pressure. The procedure followed the standard ASTM E2009-08(1014) with the exception of not using an oxygen flow through the test cell and the sample. The sample amount was $0.1-0.2 \mathrm{mg}$.

\subsection{Grease Rheology}

Rheological properties of LiX and PP grease were measured on an Anton Paar MCR 301 rheometer with a plate-plate setup and a Peltier-type heating element. To measure the complex viscosity, the temperature was gradually increased (20-140 ${ }^{\circ} \mathrm{C}, 3{ }^{\circ} \mathrm{C} / \mathrm{min}$ ) while a constant strain $(0.1 \%)$ was applied to the sample, using a plate with a diameter of $25 \mathrm{~mm}$ and a gap height of $1 \mathrm{~mm}$. The strain value was chosen so that tests were performed in the linear viscoelastic (LVE) region. Prior to testing, a relaxation time of $5 \mathrm{~min}$ at $20{ }^{\circ} \mathrm{C}$ was allowed for, and measurements were carried out at an angular frequency of $10 \mathrm{rad} / \mathrm{s}$. To determine the yield stress and flow point, strain sweep measurements were carried out at an angular frequency of $10 \mathrm{rad} / \mathrm{s}$ and temperatures of $25,40,90$, and $130{ }^{\circ} \mathrm{C}$. To minimize wall slip effects at higher temperatures, tests were performed with a serrated plate (diameter $50 \mathrm{~mm}$ ). Grease was loaded at $20^{\circ} \mathrm{C}$ and the gap height set to $1 \mathrm{~mm}$. Afterwards, the temperature was increased at a rate of $3{ }^{\circ} \mathrm{C} / \mathrm{min}$ while the grease sample was at rest, and tests were started $10 \mathrm{~min}$ after a set temperature value was reached. The strain was then increased from 0.01 to $1000 \%$.

\subsection{Pin-On-Disk Experiments}

To assess the performance of the grease blends, pin-ondisk (POD) experiments were performed using a Mini Traction Machine (MTM) of type MTM2 by PCS Instruments. The test conditions for all experiments are summarized in Table 3.

The first series of experiments (POD RT) was carried out at room temperature (RT) with IL concentrations of 2 and $5 \mathrm{wt} \%$. Here, the aim was to screen the friction and wear performance of different grease blends and to establish a reference for tests at elevated temperatures.

Based on the initial screening results, two ILs were then selected for further testing. In test series POD 90, the temperature was increased to $90{ }^{\circ} \mathrm{C}$, and grease blends with $10 \mathrm{wt} \%$ IL concentration were added to the test matrix.

Finally, test series POD 130 was designed to provide first insights into the tribological performance at high temperatures $\left(130{ }^{\circ} \mathrm{C}\right)$. Based on findings from series POD RT and POD 90, tests were limited to IL concentrations of $2 \mathrm{wt} \%$.

In all experiments, commercially available AISI 52100 steel balls (diameter $6 \mathrm{~mm}$, quality grade G20 according to ISO 3290 [49], hardness $\geq 62 \mathrm{HRC}$, roughness $R_{\mathrm{a}} \leq 0.032 \mu \mathrm{m}$ ) and steel bearing washers (hardness $\geq 62$ HRC, roughness $R_{\mathrm{a}}=0.1 \mu \mathrm{m}$ ) were used as pins and disks, respectively. Before testing, specimens were cleaned with acetone in an ultrasonic bath for half an hour, rinsed with 2-propanol, and dried in ambient air. Afterwards, about $0.3 \mathrm{~g}$ of grease was applied to the disk.

During the tests, the friction coefficient was recorded with a frequency of $1 \mathrm{~Hz}$; a grease scoop made from polytetrafluoroethylene was used to prevent starvation of the contact track.

\subsection{Wear Measurements and Surface Analysis}

After the pin-on-disk experiments, the wear scar diameters on the pins were measured in two perpendicular directions using an optical microscope of type MM-60 manufactured 
by Nikon. The average of both measurements was used for further analysis. For selected pins, the topography and elemental composition of the worn surfaces were analyzed using SEM and EDX (accelerating voltage $15 \mathrm{keV}$ ) on a Hitachi S-3700 N with a Bruker Quantax EDS system and XFlash 4010 detector.

\subsection{Data Analysis}

On completion of the pin-on-disk experiments, more than 170 friction curves and mean wear scar diameters were obtained. To present this data set in an accessible way, three average friction coefficients were calculated for each friction curve, based on the sliding distance ranges of $0-500 \mathrm{~m}$, 500-1 $000 \mathrm{~m}$, and $1000-1500 \mathrm{~m}$. The average friction coefficients were then summarized in a scatter diagram where error bars indicate the standard deviation of the friction coefficient within each sliding distance range. Since wear measurements were only performed at the end of the experiment, the average wear scar diameters are presented without any further modification. Instrument output data were processed using MTM-specific import routines of the Python Tribology Package [50].

\subsection{Ball-On-Disk Experiments}

To evaluate the traction performance in mixed sliding-rolling conditions, ball-on-disk experiments were carried out. Tests were performed using the MTM2 test rig mentioned above. Here, the entrainment speed $v$ between ball and disk was kept constant while the slide-to-roll ratio was varied between 0 and $195 \%$ in steps of 5\%, starting at low SRR values. For each step, the steady-state traction coefficient was measured for the case of $v_{\text {ball }}>v_{\text {disk }}$ and $v_{\text {ball }}<v_{\text {disk }}$ and averaged afterwards.

Experiments were carried out at room temperature and $90{ }^{\circ} \mathrm{C}$ for two selected ILs (again, based on the results of test series POD RT). Within the limitations of the test rig capabilities, the experimental conditions follow those of the pin-on-disk experiments; a complete overview is given in Table 3.

Steel bearing washers were used as disks (properties see Sect. 2.3); the properties of the AISI 52100 ball specimens (diameter $19.05 \mathrm{~mm}$ ) are comparable to those of the pins (hardness $\geq 62.5 \mathrm{HRC}, R_{\mathrm{a}}<0.02 \mu \mathrm{m}$ ). The cleaning procedure, grease amount, and grease scoop setup follow that of the pin-on-disk experiments. To ensure even grease distribution at the beginning of the experiment, the disk was rotated for at least $1 \mathrm{~min}$ with a tangential velocity of $0.2 \mathrm{~m} / \mathrm{s}$ before the ball was brought into contact. For each test, a new set of ball and disk specimens was used. Wear was not quantifiable due to the short run time.

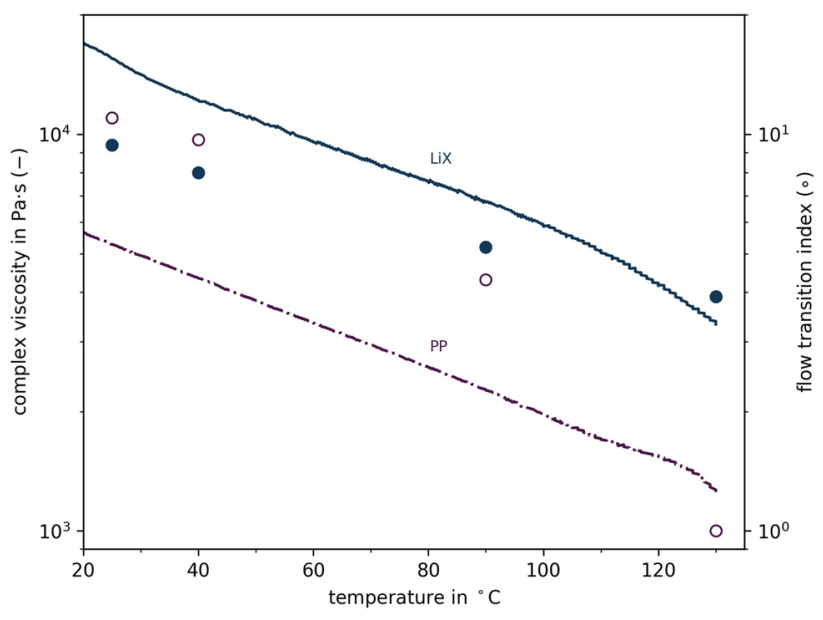

Fig. 1 Complex viscosity and flow transition index of LiX (filled circle) and PP (open circle) greases as a function of temperature

\section{Results}

\subsection{Grease Rheology}

Although both greases have the same NLGI grade, the complex viscosity of PP is significantly lower than that of $\mathrm{LiX}$ (see Fig. 1). As temperature increases, the relative change in complex viscosity is comparable for both grease types.

To quantify the flow behavior in more detail, Fig. 1 also shows the flow transition index (FTI), which is defined as the ratio between the stress in the flowpoint (storage modulus is equal to loss modulus, $\mathrm{G}^{\prime}=\mathrm{G}^{\prime \prime}$ ) and the yield stress.

Simply speaking, the closer the value of the flow transition index is to 1 , the more immediate the transition from elastic behavior to plastic flow, i.e., for a grease with FTI $=1$, the sample will start to flow immediately as soon as it is deformed.

As can be seen, FTI is well correlated with the complex viscosity for both grease types up to $90{ }^{\circ} \mathrm{C}$, decreasing logarithmically as temperature increases. Yet, for PP grease a sudden drop in FTI can be observed between 90 and $130{ }^{\circ} \mathrm{C}$, reaching an FTI of 1.0 at $130^{\circ} \mathrm{C}$, thus indicating a significantly reduced resistance to deformation at higher temperatures.

\subsection{Pin-on-Disk at Room Temperature}

The friction and wear results for test series POD RT are summarized in Figs. 2 and 3 (left panels). For LiX and PP base greases, the steady-state friction coefficient stabilizes in the range of $0.09-0.12(\mathrm{LiX})$ and $0.11-0.13$ (PP) towards the end of all experiments. Thus, on average, lower friction is observed for LiX grease. In terms of wear, experiments with PP grease are more repeatable, 


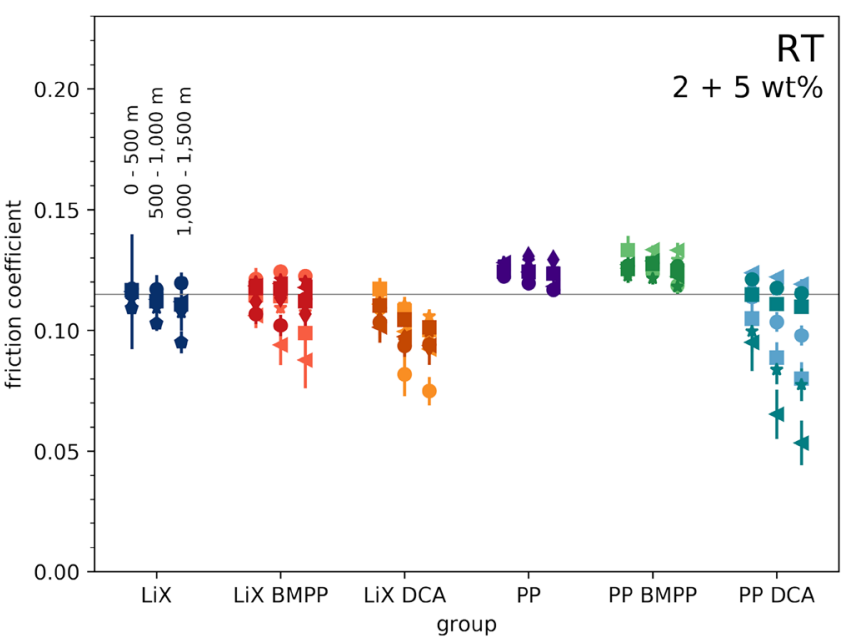

Fig. 2 Friction (left) and wear (right) results of pin-on-disk test series POD RT for $\left[\mathrm{P}_{6,6,6,14}\right][\mathrm{DCA}]$ and $\left[\mathrm{P}_{6,6,6,14}\right][\mathrm{BMPP}]$ additives. For the friction plots, each data point represents the average friction coefficient within a sliding distance range of either 0-500 m, 500-1 $000 \mathrm{~m}$, or $1000-1500 \mathrm{~m}$ (from left to right for each group). The error bars indicate the standard deviation of the friction coefficient within the

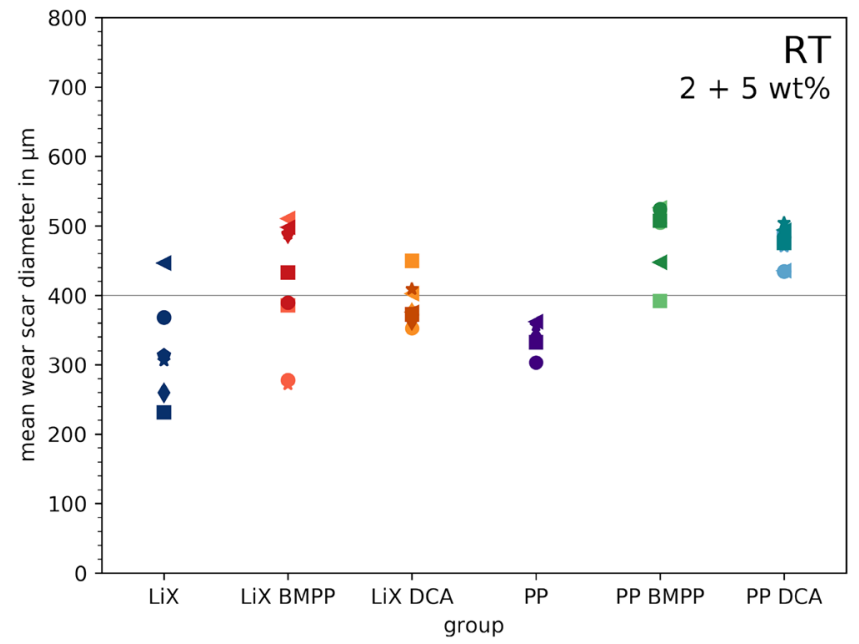

distance range. Within each group, darker colors indicate higher IL concentrations (dark $\rightarrow 5 \mathrm{wt} \%$, light $\rightarrow 2 \mathrm{wt} \%$ ). For the wear results, each data point represents the mean wear scar diameter on the pin, measured after $1.5 \mathrm{~km}$ of sliding. Comparing friction and wear data, points with the same marker symbol belong to the same test run. The horizontal line is provided to guide the eye
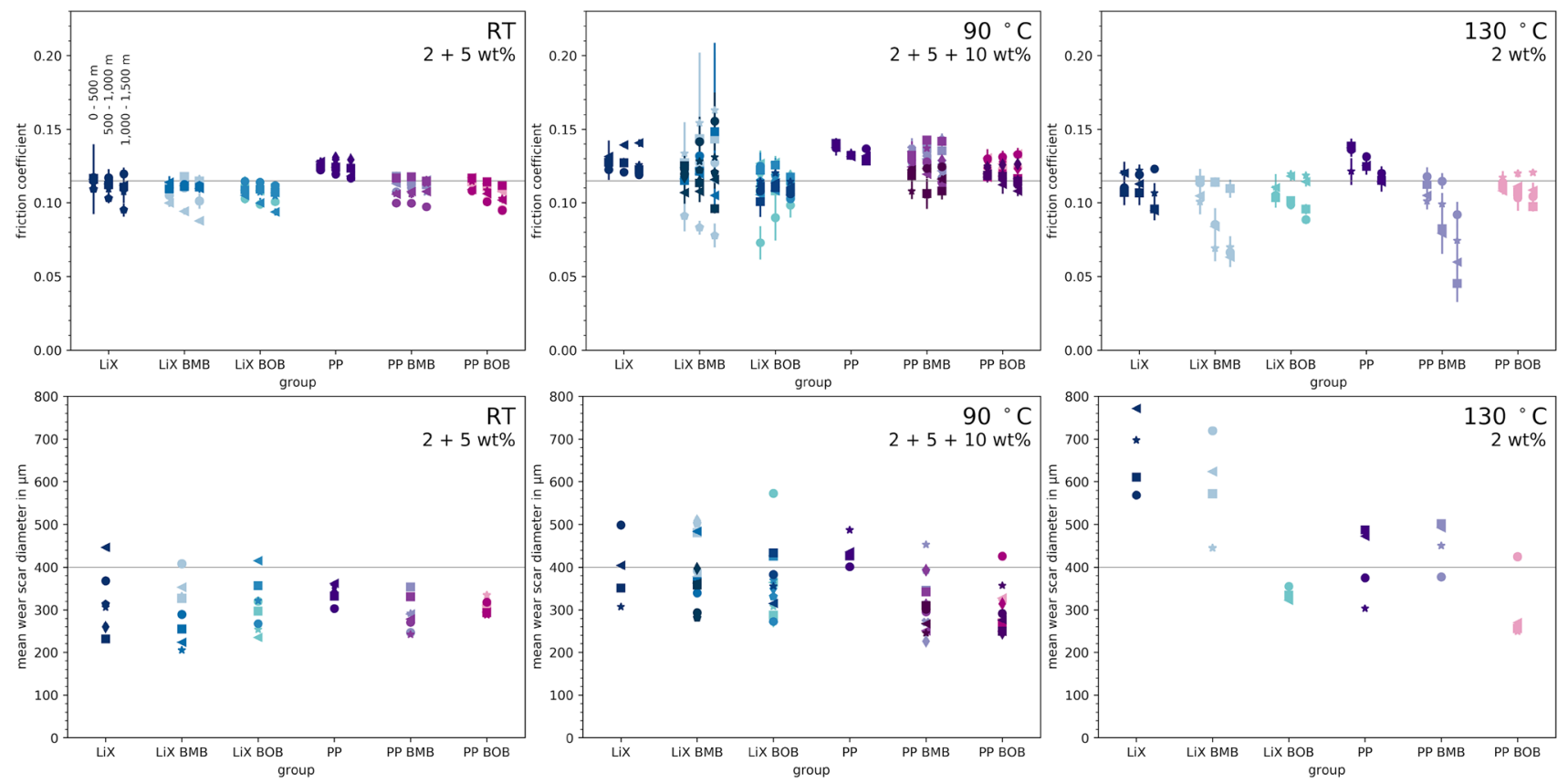

Fig. 3 Friction (top) and wear (bottom) results of pin-on-disk test series POD RT, POD 90, and POD 130 for $\left[\mathrm{P}_{6,6,6,14}\right][\mathrm{BMB}]$ and $\left[\mathrm{P}_{6,6,6,14}\right][\mathrm{BOB}]$ in the same manner as Fig. 2 . The data for the neat

yet the average wear scar diameter is comparable for both base grease types. Finally, no correlation between friction and wear is found.

Adding $\left[\mathrm{P}_{6,6,6,14}\right][\mathrm{BMPP}]$ to $\mathrm{LiX}$ and PP base grease, friction remains unchanged; however, on average, wear base greases are identical to that shown in Fig. 2. Within each group, darker colors indicate higher IL concentrations (dark $\rightarrow 10 \mathrm{wt} \%$, medium $\rightarrow 5$ wt $\%$, light $\rightarrow 2$ wt $\%$ )

increases by about $80-100 \mu \mathrm{m}$ for both grease types and is independent of additive concentration. Similar to the neat base greases, the wear results are more consistent for PP.

An increase in wear scar diameter is also found when $\left[\mathrm{P}_{6,6,6,14}\right][\mathrm{DCA}]$ is added to PP and LiX base grease. The 
increase is more pronounced for PP grease; however, so is the reduction in friction that comes with it, reaching friction coefficients as low as 0.05 . Here, the results may indicate a dependence on additive concentration-lower friction coefficients for higher IL concentrations-, but poor repeatability means that the data ultimately remain inconclusive.

When $\left[\mathrm{P}_{6,6,6,14}\right][\mathrm{BOB}]$ is added to $\mathrm{PP}$ base grease, friction decreases by about 10-20\% (Fig. 3, top left panel). On average, the wear scar diameter remains unchanged with respect to the base grease, and neither friction nor wear shows any dependence on additive concentration (Fig. 3, bottom left panel). Similar trends are found for LiX base grease: the reduction in friction with respect to the base grease is small, and both friction and wear are independent of the additive concentration.

In contrast, the results for $\left[\mathrm{P}_{6,6,6,14}\right][\mathrm{BMB}]$ may indicate a weak dependence on additive concentration: For LiX grease, wear is found to be consistently lower for higher IL concentrations. At the same time, friction remains unchanged with respect to the base grease, indicating that, at room temperature, $\left[\mathrm{P}_{6,6,6,14}\right][\mathrm{BMB}]$ may have good anti-wear properties in combination with LiX grease. For PP grease, the average reduction in wear - though visible - is less pronounced, and no dependence on additive concentration is observed.

In summary, it is found that friction may reduce by $60 \%$ when $\left[\mathrm{P}_{6,6,6,14}\right][\mathrm{DCA}]$ additives are added to $\mathrm{PP}$ and $\mathrm{LiX}$ base grease in concentrations of 2 and $5 \mathrm{wt} \%$; however, this reduction in friction comes at an almost equal increase in wear scar diameter. A similar increase is also observed for $\left[\mathrm{P}_{6,6,6,14}\right][\mathrm{BMPP}]$, yet without a repeatable decrease in friction. Wear remains unchanged for $\left[\mathrm{P}_{6,6,6,14}\right][\mathrm{BOB}]$, and $\left[\mathrm{P}_{6,6,6,14}\right][\mathrm{BMB}]$ shows potential to reduce wear for both base grease types. Thus, the latter two ILs were selected for further pin-on-disk and rolling-sliding experiments.

\subsection{Pin-on-Disk at $90^{\circ} \mathrm{C}$}

The friction and wear results for test series POD 90 are summarized in Fig. 3 (center panels). For both base greases, increasing the ambient temperature to $90{ }^{\circ} \mathrm{C}$ leads to an increase in friction and wear. Again, measurements for PP grease show better repeatability, and larger scatter is observed for LiX.

When adding $\left[\mathrm{P}_{6,6,6,14}\right][\mathrm{BOB}]$ and $\left[\mathrm{P}_{6,6,6,14}\right][\mathrm{BMB}]$ additives to PP base grease, friction reduces by $10-20 \%$, similar to the results at room temperature. No correlation between additive concentration and friction coefficient is found for additive concentrations of 2 and $5 \mathrm{wt} \%$. For concentrations of $10 \mathrm{wt} \%$, however, both friction and wear are found to be consistently at the lower end of the spectrum. While the absolute reduction in friction is small here, the wear scar diameters are significantly reduced with respect to the neat base grease. Thus, at $90{ }^{\circ} \mathrm{C}$, adding $\left[\mathrm{P}_{6,6,6,14}\right][\mathrm{BOB}]$ and $\left[\mathrm{P}_{6,6,6,14}\right][\mathrm{BMB}]$ additives to $\mathrm{PP}$ base grease effectively offsets the effects of increased temperature on wear performance.

For LiX grease, the interpretation of the friction results is more ambiguous since large scatter occurred, especially in the case of $\left[\mathrm{P}_{6,6,6,14}\right][\mathrm{BMB}]$. Here, unstable friction behavior is observed for experiments with various additive concentrations, and no clear correlation between IL concentration and friction coefficient is found. While more stable, friction measurements for $\left[\mathrm{P}_{6,6,6,14}\right][\mathrm{BOB}]$ in $\mathrm{LiX}$ show a similar trend, with minor reductions in friction and no correlation between IL concentration and friction performance. On average, the wear scar diameters are slightly reduced compared to the neat base grease, yet the effect is less pronounced than for PP grease.

\subsection{Pin-on-Disk at $130^{\circ} \mathrm{C}$}

To get insights into the friction and wear performance at even higher temperatures, test series POD 130 was carried out at $130{ }^{\circ} \mathrm{C}$. The friction and wear results are summarized in Fig. 3 (right panels).

While the friction performance of the base greases is comparable to that for tests at room temperature and $90{ }^{\circ} \mathrm{C}$, an increase in wear is found, in particular for $\mathrm{LiX}$ grease. Here, the average size of the wear scar diameter is doubled with respect to the room temperature tests, and significantly larger than at $90{ }^{\circ} \mathrm{C}$.

In contrast to the results at lower temperatures, the addition of $2 \mathrm{wt} \%\left[\mathrm{P}_{6,6,6,14}\right][\mathrm{BMB}]$ leads to a pronounced reduction in friction for both grease types. While repeatability is poor, average friction coefficients as low as 0.04 are observed for PP base grease. For $\mathrm{LiX}$, the reduction in friction is - on average — of comparable magnitude. Thus, at $130{ }^{\circ} \mathrm{C},\left[\mathrm{P}_{6,6,6,14}\right][\mathrm{BMB}]$ shows a clear potential to reduce friction for both base grease types. Also, on closer inspection, it can be seen that friction and wear are reversely-if weakly - correlated for $\left[\mathrm{P}_{6,6,6,14}\right][\mathrm{BMB}]$ and $\mathrm{PP}$ base grease, which means that low friction comes at the cost of increased wear. More experiments would be required to study this correlation in more detail.

Finally, the addition of $\left[\mathrm{P}_{6,6,6,14}\right][\mathrm{BOB}]$ additives has little effect on friction, but wear is significantly reduced. For both base grease types, wear is observed to drop to room temperature levels, which corresponds to an average wear reduction of $50 \%$ for $\mathrm{LiX}$.

In conclusion, it is found that, at $130{ }^{\circ} \mathrm{C}$, low concentrations of $\left[\mathrm{P}_{6,6,6,14}\right][\mathrm{BMB}]$ can lead to significant reductions in friction for both base grease types; in contrast, $\left[\mathrm{P}_{6,6,6,14}\right]$ [BOB] performs well as an anti-wear additive. 

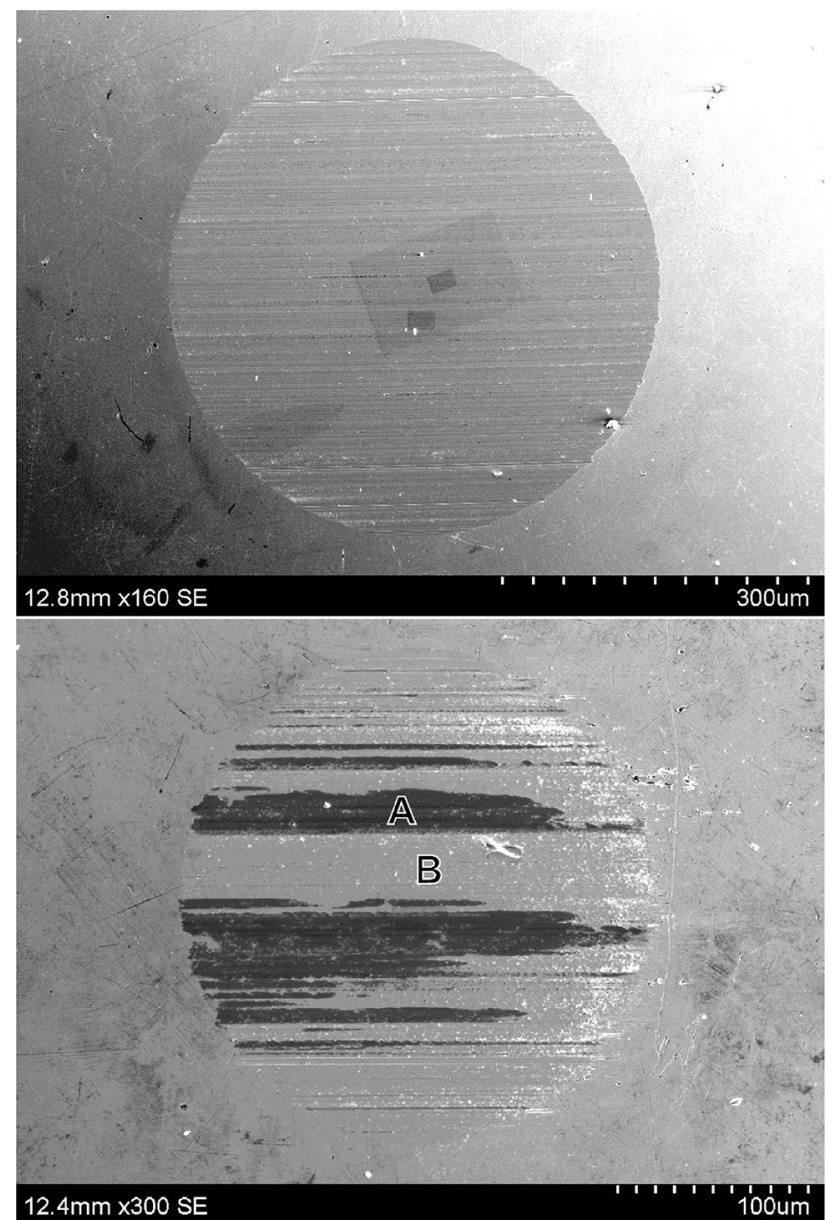

Fig. 4 SEM image of typical wear scar obtained after pin-on-disk experiments with $2 \mathrm{wt} \%\left[\mathrm{P}_{6,6,6,14}\right][\mathrm{BMB}]$ (top) and $\left[\mathrm{P}_{6,6,6,14}\right][\mathrm{BOB}]$ (bottom) in PP grease at $130{ }^{\circ} \mathrm{C}$. The pin specimens belong to the experiments with marker type square (filled square) in Fig. 3 (right)

\subsection{SEM and EDX Analysis}

Following the pin-on-disk experiments, SEM/EDX analysis was carried out for two selected pin samples from test series POD 130. Since similar friction and wear performance is observed independent of base grease type - a reduction in friction for $\left[\mathrm{P}_{6,6,6,14}\right][\mathrm{BMB}]$, and a reduction in wear for $\left[\mathrm{P}_{6,6,6,14}\right][\mathrm{BOB}]$-, both pin specimens were selected from experiments with $\mathrm{PP}$ grease [see marker type square (filled square) in Fig. $3,130^{\circ} \mathrm{C}$, data for PP grease].

Figure 4 shows SEM wear scar images of the two pin specimens, based on secondary electron collection. For $\left[\mathrm{P}_{6,6,6,14}\right][\mathrm{BMB}]$ (top), the wear scar image shows no distinct surface features, except for the evenly distributed scratch marks that run horizontally over the contact region.

For $\left[\mathrm{P}_{6,6,6,14}\right][\mathrm{BOB}]$, however, large parts of the wear scar surface appear darker than the reference area outside of the wear scar. Images from optical microscopy confirm that similar surface features are present on all pin specimens from
Table 4 Absolute elemental composition in wt $\%$ as obtained in areas $\mathrm{A}$ and $\mathrm{B}$ of the wear scar shown in Fig. 4

\begin{tabular}{lrr}
\hline Element & Area A & Area B \\
\hline Oxygen & 3.97 & n/a \\
Silicon & 0.28 & 0.34 \\
Chromium & 1.36 & 1.41 \\
Iron & 88.62 & 92.98 \\
Phosphorus & 0.02 & 0.02 \\
Manganese & 0.56 & 0.61 \\
\hline
\end{tabular}

this test series (both $\mathrm{LiX}$ and $\mathrm{PP}$ ) if $\left[\mathrm{P}_{6,6,6,14}\right][\mathrm{BOB}]$ was used as an additive-with the exception of a single experiment with PP grease that produced a relatively large mean wear scar diameter of $425 \mu \mathrm{m}$ [see marker type dot (filled circle) in Fig. $3,130^{\circ} \mathrm{C}$ ]. Thus, a clear correlation is found between the appearance of dark surface features and a reduction in wear.

As shown in Table 4, EDX spectra recorded in different regions of the worn surface (see Fig. 4, bottom) reveal increased levels of oxygen inside the darker areas; yet, except for typical alloying elements of AISI 52100 steel, no other elements are present in significant quantities. In particular, the EDX analysis does not show signs of tribofilms containing boron compounds, which were clearly detected in other tests with $\left[\mathrm{P}_{6,6,6,14}\right][\mathrm{BMB}][29]$.

\subsection{Traction Tests at Room Temperature}

The results of test series SRR RT are summarized in Fig. 5 (left panels) for LiX (top) and PP (bottom) base grease. For both grease types, the data show a steady increase in traction with increasing SRR values, approaching a sliding friction coefficient of 0.1 . This is in agreement with the results from the pin-on-disk tests at room temperature (see Fig. 3, left).

For LiX grease, adding $10 \mathrm{wt} \%\left[\mathrm{P}_{6,6,6,14}\right][\mathrm{BOB}]$ leads to a significant and repeatable reduction in traction over the entire SRR range. However, when the concentration is reduced to $2 \mathrm{wt} \%$, repeatability is poor and the traction performance is indistinguishable from that of the base grease. Thus, traction is found to be dependent on additive concentration for LiX grease and $\left[\mathrm{P}_{6,6,6,14}\right][\mathrm{BOB}]$. For PP grease, however, neither concentration of $\left[\mathrm{P}_{6,6,6,14}\right][\mathrm{BOB}]$ has a traction-reducing effect. In fact, an increase in traction may have been observed here in the central part of the SRR range.

Adding $10 \mathrm{wt} \%$ of $\left[\mathrm{P}_{6,6,6,14}\right][\mathrm{BMB}]$ has no discernible effect on traction for both base grease types. While a slight reduction may have been observed for LiX grease, the difference (compared to the neat base grease) is ultimately within the precision limit of the measurement approach. Again, a reduction in concentration to $2 \mathrm{wt} \%$ may lead to an increase in traction for PP grease within the central SRR range. 

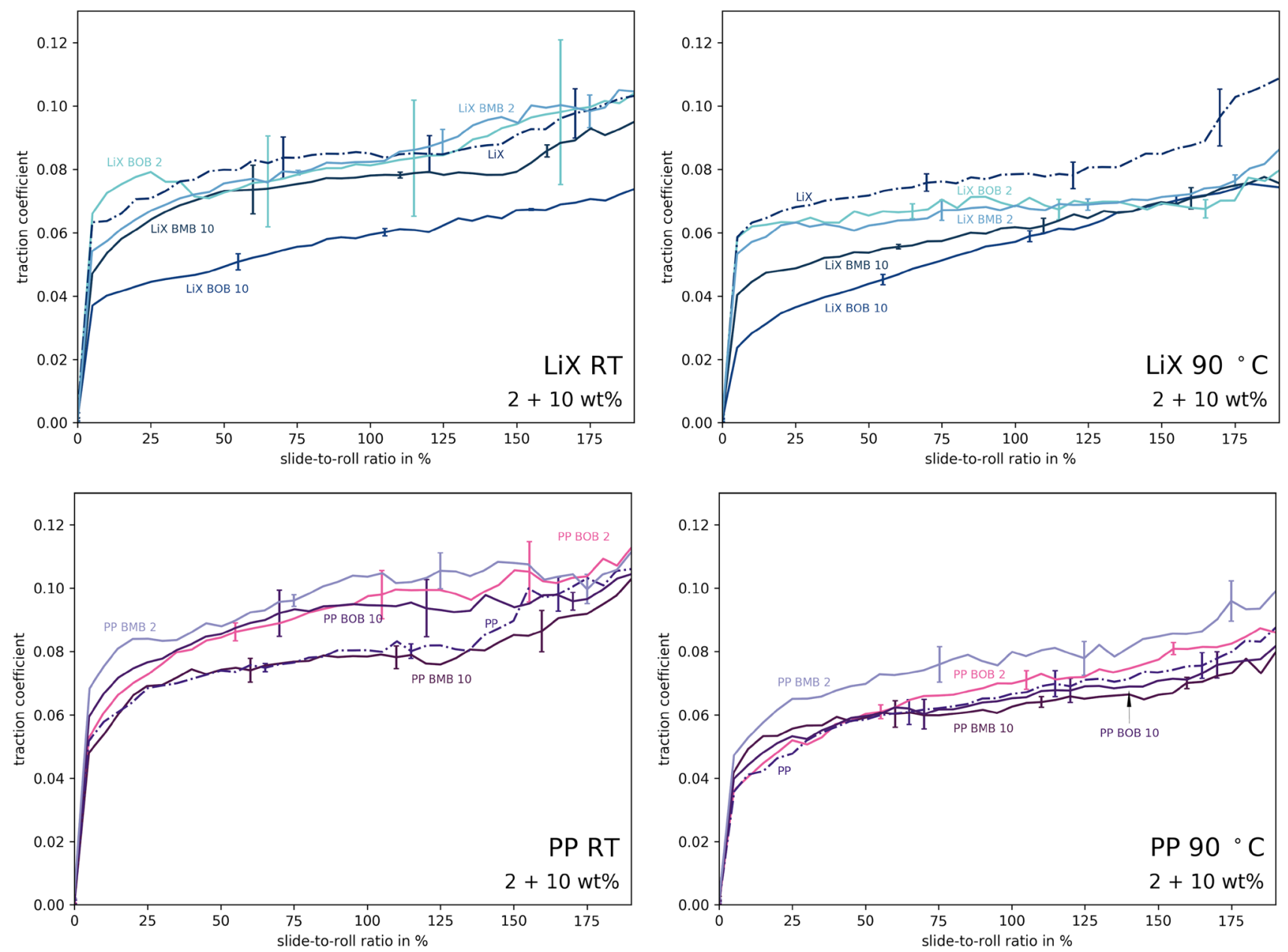

Fig. 5 Traction as a function of slide-to-roll ratio for LiX (top) and PP (bottom) grease with 2 and $10 \mathrm{wt} \%$ of $\left[\mathrm{P}_{6,6,6,14}\right][\mathrm{BOB}]$ and $\left[\mathrm{P}_{6,6,6,14}\right][\mathrm{BMB}]$. Room temperature experiments are shown on the left; experiments at $90{ }^{\circ} \mathrm{C}$ on the right. Each curve represents the

average of at least three test runs; the error bars indicate the standard deviation within the test runs. For readability, error bars are only plotted for selected SRR values

\subsection{Traction Tests at $90^{\circ} \mathrm{C}$}

Increasing the temperature to $90{ }^{\circ} \mathrm{C}$, the traction performance of neat $\mathrm{LiX}$ base grease remains unchanged within the repeatability of the experiment (Fig. 5, top right panel). For PP grease, a reduction in traction of about $15 \%$ is found for all SRR values (Fig. 5, bottom right panel).

Adding $10 \mathrm{wt} \%$ of $\left[\mathrm{P}_{6,6,6,14}\right][\mathrm{BOB}]$ to $\mathrm{LiX}$ grease leads to a significant and repeatable reduction in traction, especially at lower SRR, which is in agreement with the room temperature tests. The same can be said for $10 \mathrm{wt} \%$ of $\left[\mathrm{P}_{6,6,6,14}\right]$ [BMB] in LiX base grease, although the effect appears to be less pronounced here. For lower concentrations of either $\mathrm{IL}$, the results may indicate a slight reduction in traction for higher SRR values.

For PP grease, no IL type is found to have a significant impact on traction performance at $90{ }^{\circ} \mathrm{C}$, irrespective of additive concentration.

\section{Discussion}

For the grease systems investigated above, $\left[\mathrm{P}_{6,6,6,14}\right][\mathrm{BMPP}]$ shows little potential for friction and wear reduction. Yet, promising tribological behavior was found for this IL in other studies on the nano- and macro-scale, including a reduction in sliding friction for steel and titanium tribopairs [51-53]. The poor wear performance observed in our experiments is also not well documented in the literature, where $\left[\mathrm{P}_{6,6,6,14}\right][\mathrm{BMPP}]$ was previously found to decrease rather than increase wear $[51,52]$. Thus, our experiments indicate that results previously obtained for neat $\left[\mathrm{P}_{6,6,6,14}\right][\mathrm{BMPP}]$ may not be easily transferable to more complex tribosystems. Given the small sample size and parameter range of our experiments, further tests are required for a more general verdict on the tribological performance of this particular grease additive. 
Our findings for $\left[\mathrm{P}_{6,6,6,14}\right][\mathrm{DCA}]$ are equally limited in generalizability; nevertheless, for the grease systems studied here, the observed increase in wear limits the range of potential use cases-despite the outstanding friction performance in combination with PP grease at room temperature. Since this IL has not yet been widely used as a candidate additive in the nano- and macro-tribological community-let alone in the relatively small sub-discipline of IL grease research-, we cannot draw on a large number of published findings for comparison. However, as [DCA] anions with other types of cations have partially shown promising friction [54-57] and wear [58] performance in other studies, a change in cation may be a promising way forward here. That being said, care should be taken as ILs with [DCA] anions may produce highly toxic compounds such as hydrogen cyanide during decomposition [59].

Looking at the orthoborate ILs selected for the second stage of testing, $\left[\mathrm{P}_{6,6,6,14}\right][\mathrm{BOB}]$ shows high potential to reduce wear under severe sliding conditions. For this IL, the wear scar diameters are found to remain at room temperature levels for a wide range of temperatures. SEM/EDX analysis of selected pin specimens shows tribofilm formation; their appearance correlates well with low wear. Thus, we suggest that these films protect the steel surfaces from excessive wear under severe sliding conditions. The mechano-chemical processes that lead to the formation of the tribofilms, however, are currently not completely understood and subject of ongoing, more fundamental research in our group.

In contrast, no tribofilms were detected for grease blends with $\left[\mathrm{P}_{6,6,6,14}\right][\mathrm{BMB}]$ additives, which indicates that physical adsorption processes rather than chemical reactions may play a dominant role in the reduction in friction observed in the POD experiments. A thermogravimetric analysis shows that $\left[\mathrm{P}_{6,6,6,14}\right][\mathrm{BMB}]$ is more thermally stable than $\left[\mathrm{P}_{6,6,6,14}\right]$ [BOB]; in addition, the [BMB] anions have a stronger potential to interact electrostatically with a tribo-charged surface, facilitating the formation of low shear boundary films enriched in cations. While a detailed assessment of the friction reduction mechanism for $\left[\mathrm{P}_{6,6,6,14}\right][\mathrm{BMB}]$ is part of ongoing work, it requires a simplified lubricant system in order to-for now-bracket off the complex interaction between base oil, thickener, IL, and steel surfaces.

Looking at the above results from a more applicationoriented perspective, though, it can be concluded that, under rolling-sliding conditions, base grease type and IL concentration are deciding factors for the experimental outcome: high concentrations of $\left[\mathrm{P}_{6,6,6,14}\right][\mathrm{BOB}]$ facilitate a reduction in traction, but only for LiX base grease. At elevated temperatures, a reduction in traction is found for both orthoborate ILs at $10 \mathrm{wt} \%$ concentration-again, only for LiX.

To explain these observations, it is worth noting that the test conditions of the SRR tests are less severe compared to those of the POD tests. Firstly, the test duration is much shorter, leaving little time for surface and grease degradation processes to take place, let alone tribo-chemical reactions. Secondly, due to the high levels of rolling at lower slide-toroll ratios, the accumulated friction energy input is greatly reduced compared to the rather severe sliding tests. Thus, differences in lubricant performance are likely caused by the physical interaction between additive, thickener and steel surface, rather than the mechano-chemical processes that are typically associated with the formation of solid tribofilms.

In previous ball-on-disc experiments with PP and LiX greases, it was found that PP grease forms significantly thicker lubricating films at low to moderate speeds (and temperatures) compared to LiX grease [47], despite its nominally lower complex viscosity. This was attributed to lumps of PP thickener increasing the local film thickness by purely mechanical means. Hence, in our case, the inherent film-forming properties of PP grease may overshadow ion adsorption processes which occur on much smaller scalesand constitute one of the fundamental mechanisms of friction and wear reduction in IL-lubricated contacts [19, 22].

This is in agreement with the fact that the traction-reducing effect of $\left[\mathrm{P}_{6,6,6,14}\right][\mathrm{BOB}]$ in LiX grease becomes more pronounced as temperature increases, which can likely be attributed to a temperature-induced change in oil bleed behavior and IL solubility, as well as a reduction in base grease film-forming capabilities [47]. As a result, the inherent film-forming properties of $\mathrm{LiX}$ are reduced to a point where IL adsorption becomes relevant. Following this line of thought for the case of PP grease, a further increase in temperature to $130{ }^{\circ} \mathrm{C}$ - though hardly relevant from an application point of view-may lead to a more visible additive expression in the SRR tests.

Moreover, the SRR experiments show that the additive expression is most pronounced at low-to-medium slide-toroll ratios: the more the conditions approach pure sliding, the less important the lubricant composition. One reading of these results is that the film-forming abilities of the two base greases become more similar at higher levels of sliding - assuming that no degradation and aging processes have occurred yet.

This hypothesis finds support in the POD experiments, where friction and wear performance are similar for both grease types and additive concentrations during the first $500 \mathrm{~m}$ of sliding. The tests with $\left[\mathrm{P}_{6,6,6,14}\right][\mathrm{BMB}]$ clearly show that the additive expression only becomes pronounced in later stages of the experiments-although the frictionreducing effect does not seem to stem from the progressive (and potentially slow) build-up of chemical reaction films. ${ }^{1}$ Thus, we suggest that grease degradation processes play a vital role in the POD tests. Similar to the loss in film-forming

\footnotetext{
${ }^{1}$ In case of $\left[\mathrm{P}_{6,6,6,14}\right][\mathrm{BOB}]$, it is unclear at what stage of the experiment tribofilm formation starts to occur.
} 


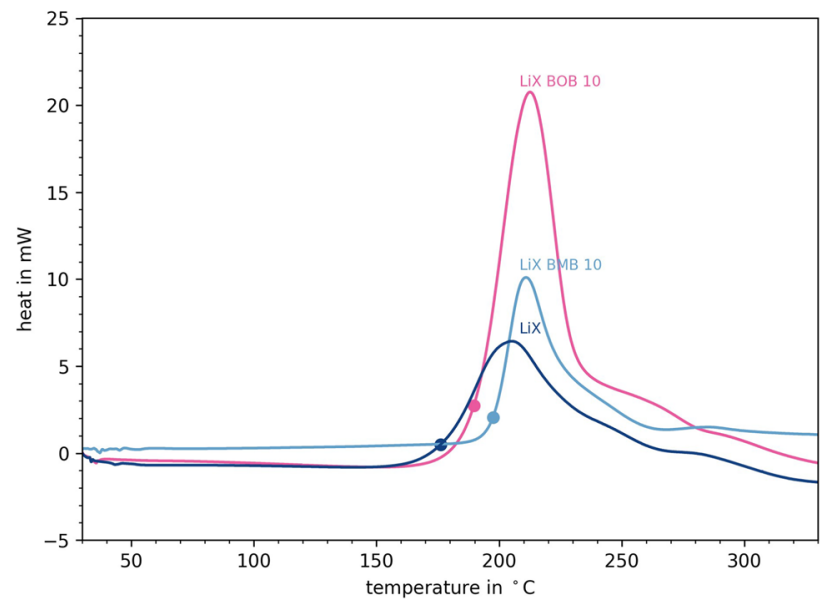

Fig. 6 Oxidative stability measurements for LiX grease. Measurements were performed for the neat base grease as well as grease blends with $10 \mathrm{wt} \%\left[\mathrm{P}_{6,6,6,14}\right][\mathrm{BMB}]$ and $\left[\mathrm{P}_{6,6,6,14}\right][\mathrm{BOB}]$. The dots mark the oxidation onset temperature, which increases for grease blends containing IL additives. The difference in intensity of the thermograms is due to a slightly different amount of grease samples used

abilities described above, grease degradation may be accelerated at elevated temperatures, giving better surface access to the ILs as sliding distance increases.

Previous studies have investigated the effect of aging and metal debris on grease performance $[60,61]$. Here, it was found that when LiX grease is thermally stressed and metal debris enters the grease, samples show structural changes (due to oxidation) that cause a decrease in oil release and a loss of ability to replenish the contact. The resulting thickening of the grease then sets off a self-enhancing cycle of increasing wear as more metal debris enters the grease, further accelerating the aging process.

The catalytic effect of metal debris also increases the thickener degradation rate for PP grease, effectively increasing the complex viscosity [60]. However, in contrast to LiX grease, the resulting increase in friction (and therefore temperature) will then cause local melting of the polypropylene thickener and essentially liquefy the grease, thereby replenishing the contact and reducing the temperature.

Thus, while LiX grease enters into a thermal runaway reaction at its end of life, PP grease continues to replenish the contact through a self-regulating cycle of heating and cooling before the lubricant finally becomes too thick for efficient lubrication [60].

Since an increase in temperature will accelerate the above processes, we suggest that the increase in wear for LiX grease at $130{ }^{\circ} \mathrm{C}$ indicates an imminent lubrication failure due to thickening of the grease. As a result, the integrity of the tribological contact increasingly relies on the IL additives, which not only help to reduce friction $\left(\left[\mathrm{P}_{6,6,6,14}\right]\right.$ $[\mathrm{BMB}])$ and wear $\left(\left[\mathrm{P}_{6,6,6,14}\right][\mathrm{BOB}]\right)$, but may also retard oxidation (as shown in Fig. 6). Similarly, additive expression at $130{ }^{\circ} \mathrm{C}$ may become more pronounced in case of PP grease as liquefaction processes increase additive solubility and general access to the surface.

\section{Conclusions}

Pin-on-disk and ball-on-disk experiments were carried out for PP and LiX grease blends containing non-halogenated phosphonium ILs at concentrations of 2-10 wt\%. Generally, the performance limits of the greases can be significantly extended by adding ILs. In particular, we find the following:

- In pin-on-disk tests, $\left[\mathrm{P}_{6,6,6,14}\right][\mathrm{BOB}]$ reduces wear over a wide temperature range compared to the neat base greases, while sliding friction is slightly reduced. The reduction in wear scar diameter is especially large-up to $50 \%$ - for $\mathrm{LiX}$ grease at $130{ }^{\circ} \mathrm{C}$. The decrease in wear correlates with the appearance of oxygen-rich surface features on the worn surfaces. At room temperature, adding 2 and $5 \mathrm{wt} \%$ of $\left[\mathrm{P}_{6,6,6,14}\right][\mathrm{BOB}]$ to $\mathrm{LiX}$ and PP base greases has only minor effects on the friction and wear performance. No clear correlation between IL additive concentration and tribological performance is found.

- In ball-on-disk tests, adding $10 \mathrm{wt} \%$ of $\left[\mathrm{P}_{6,6,6,14}\right][\mathrm{BOB}]$ to $\mathrm{LiX}$ grease reduces traction by up to $40 \%$ over a wide range of slide-to-roll ratios. This reduction does not occur for PP grease.

- For greases containing $\left[\mathrm{P}_{6,6,6,14}\right][\mathrm{BMB}]$, an increase in temperature leads to a reduction in sliding friction of up to $60 \%$, while wear is of the same order of magnitude as for the neat base grease. Only a minor influence on the friction and wear performance of LiX and PP greases is observed when adding 2 and $5 \mathrm{wt} \%$ of $\left[\mathrm{P}_{6,6,6,14}\right][\mathrm{BMB}]$ to greases at room temperature.

- $\left[\mathrm{P}_{6,6,6,14}\right][\mathrm{BMB}]$ reduces traction in rolling-sliding conditions over a wide range of slide-to-roll ratios. This reduction occurs at $90{ }^{\circ} \mathrm{C}$ and, similar to $\left[\mathrm{P}_{6,6,6,14}\right][\mathrm{BOB}]$, is observed for LiX-based greases only.

- $\left[\mathrm{P}_{6,6,6,14}\right][\mathrm{DCA}]$ additive reduces sliding friction for both base grease types at room temperature but also shows increased wear.

- $\left[\mathrm{P}_{6,6,6,14}\right][\mathrm{BMPP}]$ additive causes increased wear, but does not reduce friction in sliding contacts at room temperature.

Acknowledgements Open access funding provided by Royal Institute of Technology. We acknowledge the financial support by the Knut and Alice Wallenberg Foundation as part of project KAW2012.0078 and the Swedish Research Council as part of project 2014-4694. We are grateful to professor Oleg N. Antzutkin's group for providing the orthoborate ionic liquids. We would like to thank Ju Shu and all members of the 
I-LEAP research team for helpful discussions and valuable comments. Also, we would like to thank Sagar P. Mahabaleshwar for his help with initial screening tests.

Open Access This article is distributed under the terms of the Creative Commons Attribution 4.0 International License (http://creativeco mmons.org/licenses/by/4.0/), which permits unrestricted use, distribution, and reproduction in any medium, provided you give appropriate credit to the original author(s) and the source, provide a link to the Creative Commons license, and indicate if changes were made.

\section{References}

1. Herdan, J.M.: Lubricating oil additives and the environmentan overview. Lubr. Sci. 9(2), 161-172 (1997). https://doi. org/10.1002/1s.3010090205

2. Cai, M., Liang, Y., Yao, M., Xia, Y., Zhou, F., Liu, W.: Imidazolium ionic liquids as antiwear and antioxidant additive in poly(ethylene glycol) for steel/steel contacts. ACS Appl. Mater. Interfaces 2(3), 870-876 (2010). https://doi.org/10.1021/am900 $847 \mathrm{j}$

3. Cai, M., Liang, Y., Zhou, F., Liu, W.: A novel imidazolium salt with antioxidation and anticorrosion dual functionalities as the additive in poly(ethylene glycol) for steel/steel contacts. Wear 306, 197-208 (2013). https://doi.org/10.1016/j.wear.2012.09.001

4. Fan, M., Song, Z., Liang, Y., Zhou, F., Liu, W.: In situ formed ionic liquids in synthetic esters for significantly improved lubrication. ACS Appl. Mater. Interfaces 4(12), 6683-6689 (2012). https ://doi.org/10.1021/am3018042

5. Grace, J., Vysochanska, S., Lodge, J., Iglesias, P.: Ionic liquids as additives of coffee bean oil in steel-steel contacts. Lubricants 3(4), 637-649 (2015). https://doi.org/10.3390/lubricants3040637

6. Khemchandani, A., Somers, P., Howlett, A., Jaiswal, E., Sayanna, M.: Forsyth, A biocompatible ionic liquid as an antiwear additive for biodegradable lubricants. Tribol. Int. 77, 171-177 (2014). https://doi.org/10.1016/j.triboint.2014.04.016

7. Pejaković, V., Tomastik, C., Dörr, N., Kalin, M.: Influence of concentration and anion alkyl chain length on tribological properties of imidazolium sulphate ionic liquids as additives to glycerol in steel-steel contact lubrication. Tribol. Int. 97, 234-243 (2016). https://doi.org/10.1016/j.triboint.2016.01.034

8. Shanhua, Q., Xuliang, C., Liguo, L., Qingzhong, L.: Tribological properties of the castor oil affected by the additive of the ionic liquid [HMIM]BF4. J. Tribol. 138(1), 014501 (2016). https://doi. org/10.1115/1.4031081

9. Somers, A.E., Khemchandani, B., Howlett, P.C., Sun, J., MacFarlane, D.R., Forsyth, M.: Ionic liquids as antiwear additives in base oils: influence of structure on miscibility and antiwear performance for steel on aluminum. ACS Appl. Mater. Interfaces 5(22), 11544-11553 (2013). https://doi.org/10.1021/am4037614

10. Yao, M., Liang, Y., Xia, Y., Zhou, F.: Bisimidazolium ionic liquids as the high-performance antiwear additives in poly(ethylene glycol) for steel-steel contacts. ACS Appl. Mater. Interfaces 1(2), 467-471 (2009). https://doi.org/10.1021/am800132z

11. Blanco, D., Battez, A.H., Viesca, J., González, R., FernándezGonzález, A.: Lubrication of CrN coating with ethyl-dimethyl2-methoxyethylammonium tris(pentafluoroethyl)trifluorophosphate ionic liquid as additive to PAO 6. Tribol. Lett. 41(1), 295-302 (2011). https://doi.org/10.1007/s11249-010-9714-1

12. Fu, X., Sun, L., Zhou, X., Li, Z., Ren, T.: Tribological study of oil-miscible quaternary ammonium phosphites ionic liquids as lubricant additives in PAO. Tribol. Lett. (2015). https://doi. org/10.1007/s11249-015-0596-0
13. Zhou, Y., Dyck, J., Graham, T.W., Luo, H., Leonard, D.N., Qu, J.: Ionic liquids composed of phosphonium cations and organophosphate, carboxylate, and sulfonate anions as lubricant antiwear additives. Langmuir 30(44), 13301-13311 (2014). https:// doi.org/10.1021/1a5032366

14. Monge, R., González, R., Battez, A.H., Fernández-Gonzez, A., Viesca, J., García, A., Hadfield, M.: Ionic liquids as an additive in fully formulated wind turbine gearbox oils. Wear (2015). https ://doi.org/10.1016/j.wear.2015.01.041

15. Anand, M., Hadfield, M., Viesca, J., Thomas, B., Battez, A.H., Austen, S.: Ionic liquids as tribological performance improving additive for in-service and used fully-formulated diesel engine lubricants. Wear (2015). https://doi.org/10.1016/j. wear.2015.01.055

16. Fernandes, C.M., Battez, A.H., González, R., Monge, R., Viesca, J., García, A., Martins, R.C., Seabra, J.H.: Torque loss and wear of FZG gears lubricated with wind turbine gear oils using an ionic liquid as additive. Tribol. Int. (2015). https://doi.org/10.1016/j. triboint.2015.04.037

17. Qu, J., Blau, P.J., Dai, S., Luo, H., Meyer, H.M.I.: Ionic liquids as novel lubricants and additives for diesel engine applications. Tribol. Lett. 35(3), 181-189 (2009). https://doi.org/10.1007/s1124 9-009-9447-1

18. Westerholt, A., Weschta, M., Bsmann, A., Tremmel, S., Korth, Y., Wolf, M., Schlcker, E., Wehrum, N., Lennert, A., Uerdingen, M., Holweger, W., Wartzack, S., Wasserscheid, P.: Halide-free synthesis and tribological performance of oil-miscible ammonium and phosphonium-based ionic liquids. ACS Sustain. Chem. Eng. 3(5), 797-808 (2015). https://doi.org/10.1021/sc500517n

19. Bermúdez, M.D., Jiménez, A.E., Sanes, J., Carrión, F.J.: Ionic liquids as advanced lubricant fluids. Molecules 14(8), 2888-2908 (2009). https://doi.org/10.3390/molecules 14082888

20. Minami, I.: Ionic liquids in tribology. Molecules 14(6), 22862305 (2009). https://doi.org/10.3390/molecules14062286

21. Zhou, F., Liang, Y., Liu, W.: Ionic liquid lubricants: designed chemistry for engineering applications. Chem. Soc. Rev. 38, 2590-2599 (2009). https://doi.org/10.1039/B817899M

22. Somers, A.E., Howlett, P.C., MacFarlane, D.R., Forsyth, M.: A review of ionic liquid lubricants. Lubricants 1(1), 3-21 (2013). https://doi.org/10.3390/lubricants 1010003

23. Xiao, H.: Ionic liquid lubricants: basics and applications. Tribol. Trans. 60(1), 20-30 (2017). https://doi.org/10.1080/10402 004.2016.1142629

24. Amiril, S., Rahim, E., Syahrullail, S.: A review on ionic liquids as sustainable lubricants in manufacturing and engineering: recent research, performance, and applications. J. Clean. Prod. 168, 1571-1589 (2017). https://doi.org/10.1016/j.jclepro.2017.03.197

25. Zhao, D., Liao, Y., Zhang, Z.: Toxicity of ionic liquids. Clean Soil Air Water 35(1), 42-48 (2007). https://doi.org/10.1002/ clen.200600015

26. Petkovic, M., Seddon, K.R., Rebelo, L.P.N., Pereira, C.S.: Ionic liquids: a pathway to environmental acceptability. Chem. Soc. Rev. 40, 1383-1403 (2011). https://doi.org/10.1039/C004968A

27. Shah, F.U., Glavatskih, S., MacFarlane, D.R., Somers, A., Forsyth, M., Antzutkin, O.N.: Novel halogen-free chelated orthoboratephosphonium ionic liquids: synthesis and tribophysical properties. Phys. Chem. Chem. Phys. 13, 12865-12873 (2011). https ://doi.org/10.1039/C1CP21139K

28. Taher, M., Shah, F.U., Filippov, A., de Baets, P., Glavatskih, S., Antzutkin, O.N.: Halogen-free pyrrolidinium bis(mandelato) borate ionic liquids: some physicochemical properties and lubrication performance as additives to polyethylene glycol. RSC Adv. 4, 30617-30623 (2014). https://doi.org/10.1039/C4RA0 2551B

29. Rohlmann, P., Munavirov, B., Furó, I., Antzutkin, O., Rutland, M.W., Glavatskih, S.: Non-halogenated ionic liquid dramatically 
enhances tribological performance of biodegradable oils. Front. Chem. 7, 98 (2019). https://doi.org/10.3389/fchem.2019.00098

30. Shah, F.U., Glavatskih, S., Antzutkin, O.N.: Boron in tribology: from borates to ionic liquids. Tribol. Lett. 51(3), 281-301 (2013). https://doi.org/10.1007/s11249-013-0181-3

31. Cai, M., Liang, Y., Zhou, F., Liu, W.: Tribological properties of novel imidazolium ionic liquids bearing benzotriazole group as the antiwear/anticorrosion additive in poly(ethylene glycol) and polyurea grease for steel/steel contacts. ACS Appl. Mater. Interfaces 3(12), 4580-4592 (2011). https://doi.org/10.1021/ am200826b

32. Cai, M., Zhao, Z., Liang, Y., Zhou, F., Liu, W.: Alkyl imidazolium ionic liquids as friction reduction and anti-wear additive in polyurea grease for steel/steel contacts. Tribol. Lett. 40(2), 215-224 (2010). https://doi.org/10.1007/s11249-010-9624-2

33. Fan, X., Wang, L.: Highly conductive ionic liquids toward high-performance space-lubricating greases. ACS Appl. Mater. Interfaces 6(16), 14660-14671 (2014). https://doi.org/10.1021/ am503941e

34. Fan, X., Wang, L., Xia, Y.: Oil-soluble lithium salts as novel lubricant additives towards improving conductivity and tribological performance of bentone grease. Lubr. Sci. 27(6), 359368 (2015). https://doi.org/10.1002/ls.1286

35. Fan, X., Xia, Y., Wang, L., Pu, J., Chen, T., Zhang, H.: Study of the conductivity and tribological performance of ionic liquid and lithium greases. Tribol. Lett. 53(1), 281-291 (2014). https ://doi.org/10.1007/s11249-013-0266-z

36. Fox, M., Priest, M.: Tribological properties of ionic liquids as lubricants and additives. Part 1: synergistic tribofilm formation between ionic liquids and tricresyl phosphate. Proc Inst Mech Eng J 222(3), 291-303 (2008). https://doi.org/10.1243/13506 501JET387

37. Ge, X., Xia, Y.B., Shu, Z.: Conductive and tribological properties of lithium-based ionic liquids as grease base oil. Tribol. Trans. 58(4), 686-690 (2015). https://doi.org/10.1080/10402 004.2015 .1012772

38. Song, Z., Fan, M., Liang, Y., Zhou, F., Liu, W.: Lithium-based ionic liquids: in situ-formed lubricant additive only by blending. Tribol. Lett. 49(1), 127-133 (2013). https://doi.org/10.1007/ s11249-012-0046-1

39. Wang, Z., Xia, Y., Liu, Z.: Comparative study of the tribological properties of ionic liquids as additives of the attapulgite and bentone greases. Lubr. Sci. 24(4), 174-187 (2012). https://doi. org/10.1002/1s. 1173

40. Wang, Z., Xia, Y., Liu, Z., Wen, Z.: Conductive lubricating grease synthesized using the ionic liquid. Tribol. Lett. 46(1), 33-42 (2012). https://doi.org/10.1007/s11249-012-9915-x

41. Mu, L., Shi, Y., Ji, T., Chen, L., Yuan, R.C., Wang, H., Zhu, J.: Ionic grease lubricants: protic [triethanolamine][oleic acid] and aprotic [choline][oleic acid]. ACS Appl. Mater. Interfaces 8(7), 4977-4984 (2016). https://doi.org/10.1021/acsami.5b12261

42. Lugt, P.M.: Modern advancements in lubricating grease technology. Tribol. Int. 97, 467-477 (2016). https://doi.org/10.1016/j. triboint.2016.01.045

43. Gonçalves, D., Graça, B., Campos, A.V., Seabra, J.: On the friction behaviour of polymer greases. Tribol. Int. 93, 399-410 (2016). https://doi.org/10.1016/j.triboint.2015.09.027

44. Gonçalves, D., Pinho, S., Graça, B., Campos, A.V., Seabra, J.H.: Friction torque in thrust ball bearings lubricated with polymer greases of different thickener content. Tribol. Int. 96, 87-96 (2016). https://doi.org/10.1016/j.triboint.2015.12.017

45. Gonçalves, D., Cousseau, T., Gama, A., Campos, A.V., Seabra, J.H.: Friction torque in thrust roller bearings lubricated with greases, their base oils and bleed-oils. Tribol. Int. 107, 306-319 (2017). https://doi.org/10.1016/j.triboint.2016.11.041

46. Muller, D., Matta, C., Thijssen, R., bin Yusof, M.N., van Eijk, M.C., Chatra, S.: Novel polymer grease microstructure and its proposed lubrication mechanism in rolling/sliding contacts. Tribol. Int. 110, 278-290 (2017). https://doi.org/10.1016/j.tribo int.2017.02.030

47. Gonçalves, D., Graça, B., Campos, A.V., Seabra, J., Leckner, J., Westbroek, R.: On the film thickness behaviour of polymer greases at low and high speeds. Tribol. Int. 90, 435-444 (2015). https://doi.org/10.1016/j.triboint.2015.05.007

48. Shu, J., Harris, K., Munavirov, B., Westbroek, R., Leckner, J., Glavatskih, S.: Tribology of polypropylene and Li-complex greases with ZDDP and MoDTC additives. Tribol. Int. 118, 189-195 (2018). https://doi.org/10.1016/j.triboint.2017.09.028

49. ISO 3290-1:2014: Rolling bearings-Balls-Part 1: Steel balls, 2014-09

50. Ploss, M., et al.: Tribology—a Python package for Tribology Research and Education, version v0.4.9 (1st November 2018). https://doi.org/10.5281/zenodo.1476597.5281/zenodo.1476597

51. Pena, D., McIntee, O., Zou, Q., Gara, L.: Investigation of the stability and tribological performance of ionic nanoliquids. Tribol. Trans. 60(5), 845-851 (2017). https://doi.org/10.1080/10402 004.2016 .1218094

52. Li, H., Somers, A.E., Rutland, M.W., Howlett, P.C., Atkin, R.: Combined nano- and macrotribology studies of titania lubrication using the oil-ionic liquid mixtures. ACS Sustain. Chem. Eng. 4(9), 5005-5012 (2016). https://doi.org/10.1021/acssu schemeng.6b01383

53. Cooper, P.K., Wear, C.J., Li, H., Atkin, R.: Ionic liquid lubrication of stainless steel: friction is inversely correlated with interfacial liquid nanostructure. ACS Sustain. Chem. Eng. 5(12), 11737-11743 (2017). https://doi.org/10.1021/acssuschem eng. $7 \mathrm{~b} 03262$

54. Kawada, S., Watanabe, S., Tsuboi, R., Sasaki, S., Prakash, B.: Lubrication mechanism of halogen-free ionic liquids. Tribol. Online 12(4), 155-161 (2017). https://doi.org/10.2474/ trol.12.155

55. Amorim, P., Ferraria, A., Colao, R., Branco, L., Saramago, B.: Imidazolium-based ionic liquids used as additives in the nanolubrication of silicon surfaces. Beil. J. Nanotechnol. 8(1), 1961-1971 (2017). https://doi.org/10.3762/bjnano.8.197

56. Kawada, S., Kodama, E., Sato, K., Ogawa, S., Watanabe, M., Okubo, H., Sasaki, S.: Effect of water on the interfacial structures of room-temperature ionic liquids. Surf. Interface Anal. (2018). https://doi.org/10.1002/sia.6536

57. Okubo, H., Kawada, S., Watanabe, S., Sasaki, S.: Tribological performance of halogen-free ionic liquids in steel-steel and DLC-DLC contacts. Tribol. Trans. 61(1), 71-79 (2018). https ://doi.org/10.1080/10402004.2016.1272731

58. Kondo, Y., Koyama, T., Tsuboi, R., Nakano, M., Miyake, K., Sasaki, S.: Tribological performance of halogen-free ionic liquids as lubricants of hard coatings and ceramics. Tribol. Lett. 51(2), 243-249 (2013). https://doi.org/10.1007/s1124 9-013-0159-1

59. Chambreau, S.D., Schenk, A.C., Sheppard, A.J., Yandek, G.R., Vaghjiani, G.L., Maciejewski, J., Koh, C.J., Golan, A., Leone, S.R.: Thermal decomposition mechanisms of alkylimidazolium ionic liquids with cyano-functionalized anions. J. Phys. Chem. A 118(47), 11119-11132 (2014). https://doi.org/10.1021/jp509 5855 
60. Leckner, J., Westbroek, R.: Polypropylene-a new thickener technology for energy efficient lubrication. NLGI Spokesman 81(1), 34-56 (2017)

61. Leckner, J., Westbroek, R.: Polypropylene-a novel thickener technology with many surprises, In: 29th ELGI AGM Helsinki, Finland, (2017)
Publisher's Note Springer Nature remains neutral with regard to jurisdictional claims in published maps and institutional affiliations. 